\title{
DESIGN AND STRESS ANALYSIS OF A FRAME WITH SUSPENSION TO MULTITASK TERRAIN ROVER
}

\author{
M. Pierzgalski ${ }^{*}$, K. Sokół ${ }^{* *}$, D. Cekus ${ }^{* * *}$
}

\begin{abstract}
In this paper the design and stress analysis of a frame with suspension used in Modernity terrain rover is presented. The mentioned rover was used in University Rover Challenge 2018 (Utah, USA) and finished the challenge in the first place. The results presented in this paper are achieved with the SolidWorks software. The simulations are concern on maximum stress and displacements distributions and are done for different cases such as standby mode and wheel-rock collision.
\end{abstract}

Keywords: Terrain Rover, Mechanics, Stress Analysis, Mars Rover, Frame and suspension

\section{Introduction}

The rover for which the frame and the suspension was designed is the one used by PCz Rover Team (2019) in University Rover Challenge (2018) and is called Modernity II. The rover is composed of main frame with suspension (what is the topic of this paper), set of wheels which are 3D printed and a manipulator. The main purpose of the rover designer is to meet the challenge regulations and to design a machine which will be the best in all four competitions - autonomous traversal task, sample cache task, extreme retrieval and delivery task, equipment servicing task.

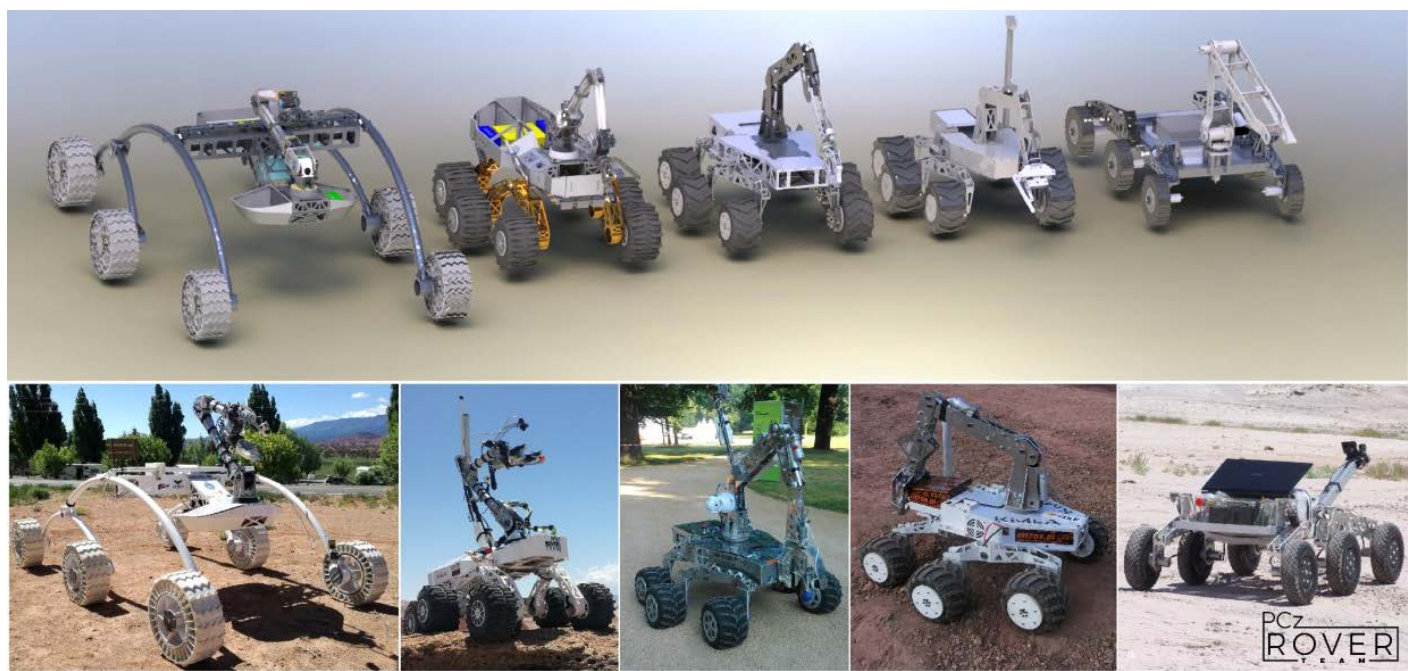

Fig. 1: Five Rovers - designs and constructions (the oldest - first from right)

Maciej Pierzgalski, MSc., Institute of Mechanics and Machine Design Foundation, Częstochowa University of Technology Dąbrowskiego 73, 42-200 Częstochowa, Poland, pierzgalski@imipkm.pcz.pl

** Krzysztof Sokół, PhD.: Institute of Mechanics and Machine Design Foundation, Częstochowa University of Technology Dąbrowskiego 73, 42-200 Częstochowa, Poland, sokol@imipkm.pcz.pl

*** Dawid Cekus, Assoc Prof.: Institute of Mechanics and Machine Design Foundation, Częstochowa University of Technology Dąbrowskiego 73, 42-200 Częstochowa, Poland, cekus@imipkm.pcz.pl 
The PCz Rover Team was founded in 2013 and during last years, five different rovers were designed and field tested in different challenges. The results of the design of one of previous rovers were published by Pierzgalski et.al. (2017). The rovers have evolved, but two elements were always constant - total mass limit set to $50 \mathrm{~kg}$ and total cost of production below $15000 \$$.

In this paper the geometrical and the computational models will be presented as well as the results of the analysis of the construction of the rover in two different cases. All those elements are done in SolidWorks (2016). The obtained results helped designers to predict and identify the weakest points in the construction and to redesign them. As a confirmation of the correctness of the design is the first place in University Rover Challenge 2018.

\section{Project, geometric model and calculation models of the suspension and frame}

On the basis of the experience gained in previous builds, this time it was decided to construct the biggest possible rover. Bigger rover can easily overcomes large obstacles. It has been also decided to change the suspension system form rocker type with two swingarms for each side to the classic rocker-bogie. The similar suspension units can be found in rover which have already touched the surface of the red planet. This suspension unit is characterized with connection of two swingarms into one. Additionally on the frame the differential bar is installed which keeps the frame in the middle position between the deflections of the swingarms - see Fig. 2.

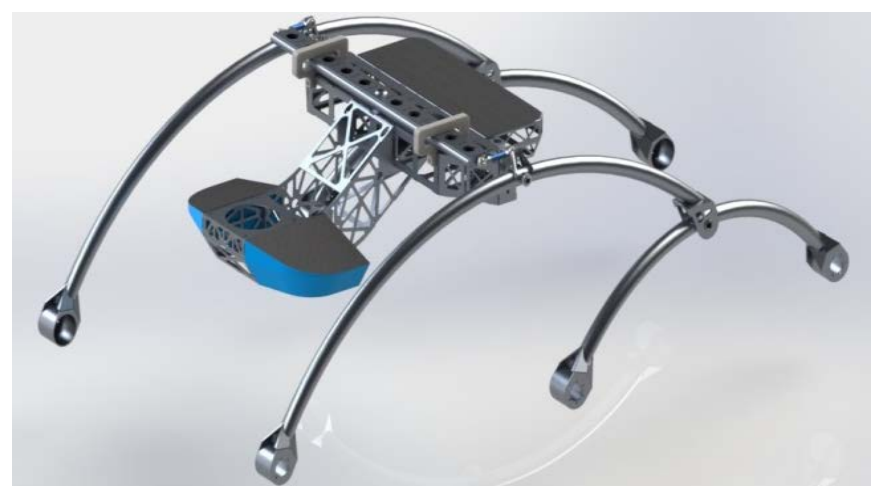

Fig. 2: Modernity II Rover, without manipulator and wheels

\subsection{Design assumptions}

Before the project phase was started the following assumptions have been done: wheelbase $-1000 \mathrm{~mm}$, width - not greater than $1400 \mathrm{~mm}$, total mass - below $50 \mathrm{~kg}$, installation of the rocker-boogie suspension, frame made of aluminum and composites.

The analysis was done with the FEM. The DOF factor of the model was 2233467 in scenario 1 and 2227614 in scenario 2. The difference in DOF results from different boundary conditions. The designed model of the rover was simplified in this stage. The elements such as containers for electronic units and slides of the differential bar were replaced with the forces which correspond to their mass - Fig. 3.

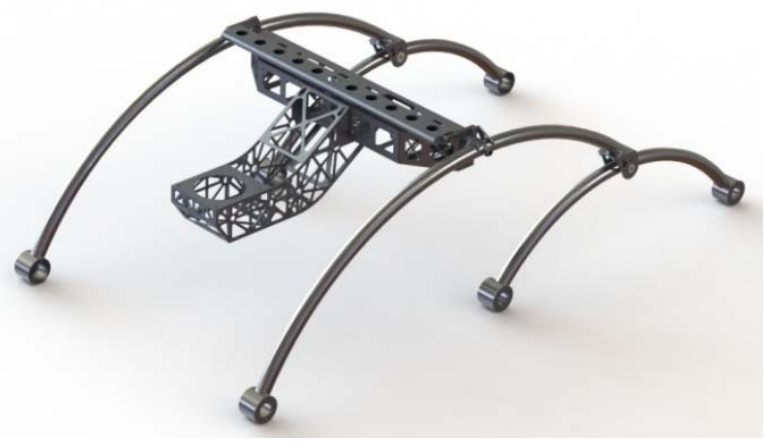

Fig. 3: Simplified geometric model 


\subsection{Calculation models}

In the simulations two different scenarios have been created: rover in standby mode, wheel-rock collision. In both cases the following external load are introduced: force which simulates the mass of the manipulator $170 \mathrm{~N}$, gravitational force, force which simulates onboard equipment $50 \mathrm{~N}$. Additionally in the second scenario the following calculations have been done in order to find the collision force:

$$
E_{K}=\mathrm{W},
$$

where $E_{K}$ is the kinetic energy and $W$ is work defined as unknown force $F$ multiplied by distance $x$ from the wheel to the obstacle. Finally the $F$ force is calculated as:

$$
F=\frac{m v^{2}}{2 x}[N] .
$$

The magnitudes of the parameters are as follows: $m=48 \mathrm{~kg}, V=2 \mathrm{~m} / \mathrm{s}$ (average speed in challanges), $x=0.08 \mathrm{~m}$. On the basis of this the magnitude of $F$ is equal to $1200 \mathrm{~N}$. The mesh parameters are as follows: automatic mode with minimum element size $0.5 \mathrm{~mm}$ and maximum $6 \mathrm{~mm}$. The mesh with all loads corresponding to the scenario 1 is presented in the Fig. 4.

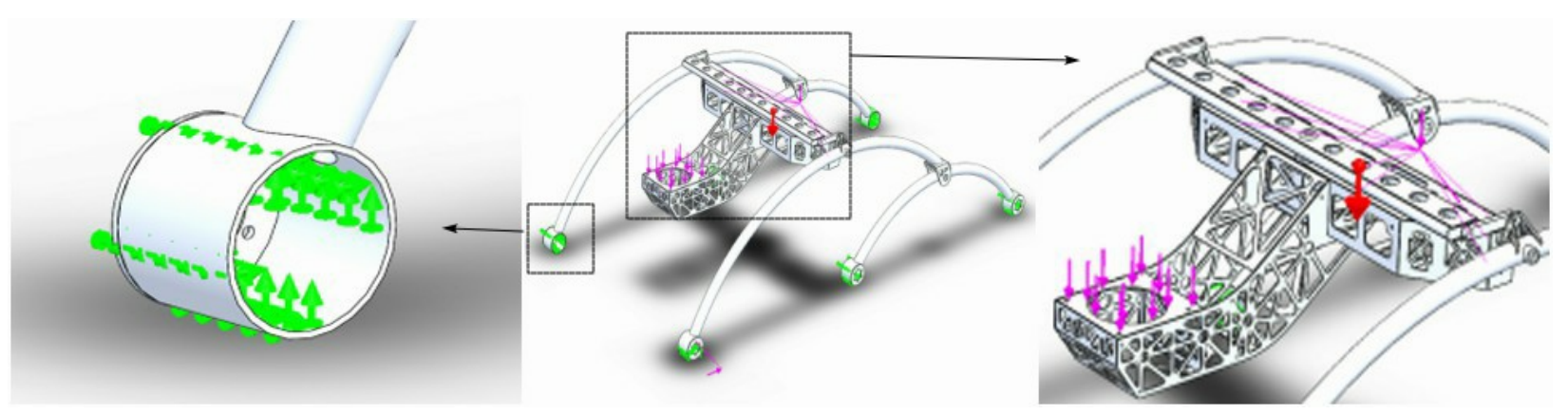

Fig. 4: FEM model (scenario 2)

\subsection{Results of simulations}

On the basis of the above assumptions the simulations have been performed in order to identify the weakest points of the construction. The sample of the results is presented in the Table 1, Fig. 5 and Fig. 6.

Tab. 1: The results of numerical analyzes

\begin{tabular}{cccc}
\hline Scenario & $\begin{array}{c}\text { The maximum von Mises } \\
\text { stress }\left[\mathrm{N} / \mathrm{mm}^{2}\right]\end{array}$ & $\begin{array}{c}\text { Maximum resultant } \\
\text { displacement }[\mathrm{mm}]\end{array}$ & $\begin{array}{c}\text { The maximum } \\
\text { equivalent strain }\end{array}$ \\
\hline 1 & 10.5 & 0.38 & 0.000624 \\
\hline 2 & 170 & 46.157 & 0.011042 \\
\hline
\end{tabular}
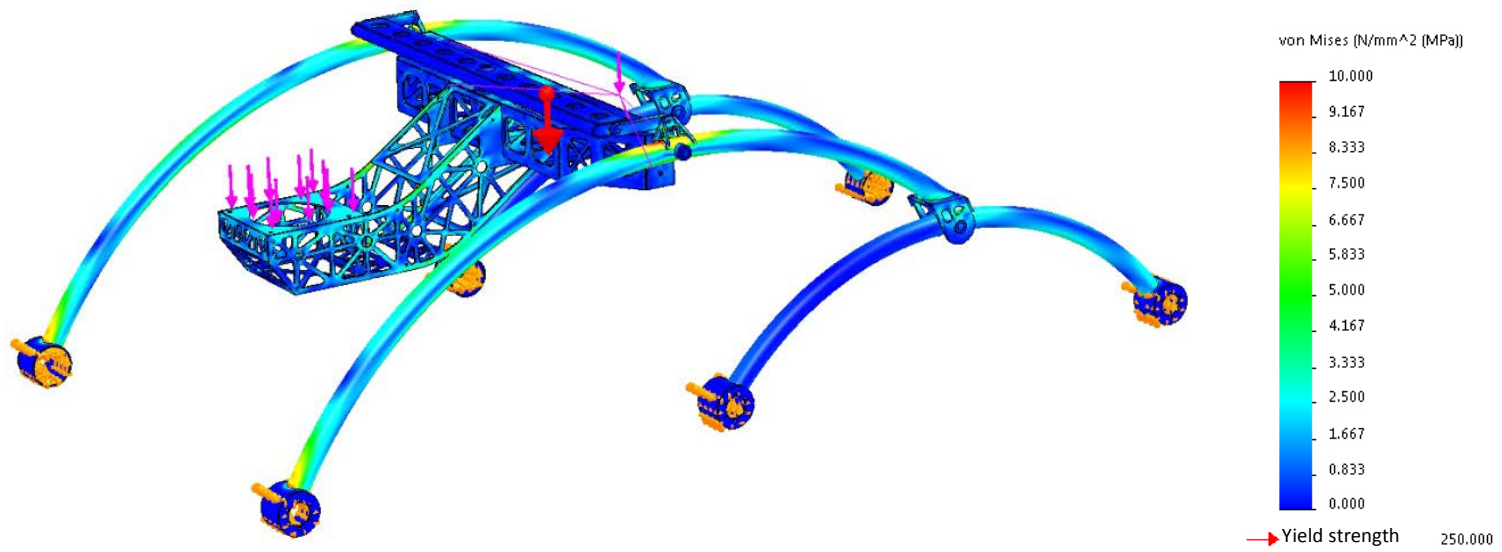

Fig. 5: First scenario the von Mises stresses 


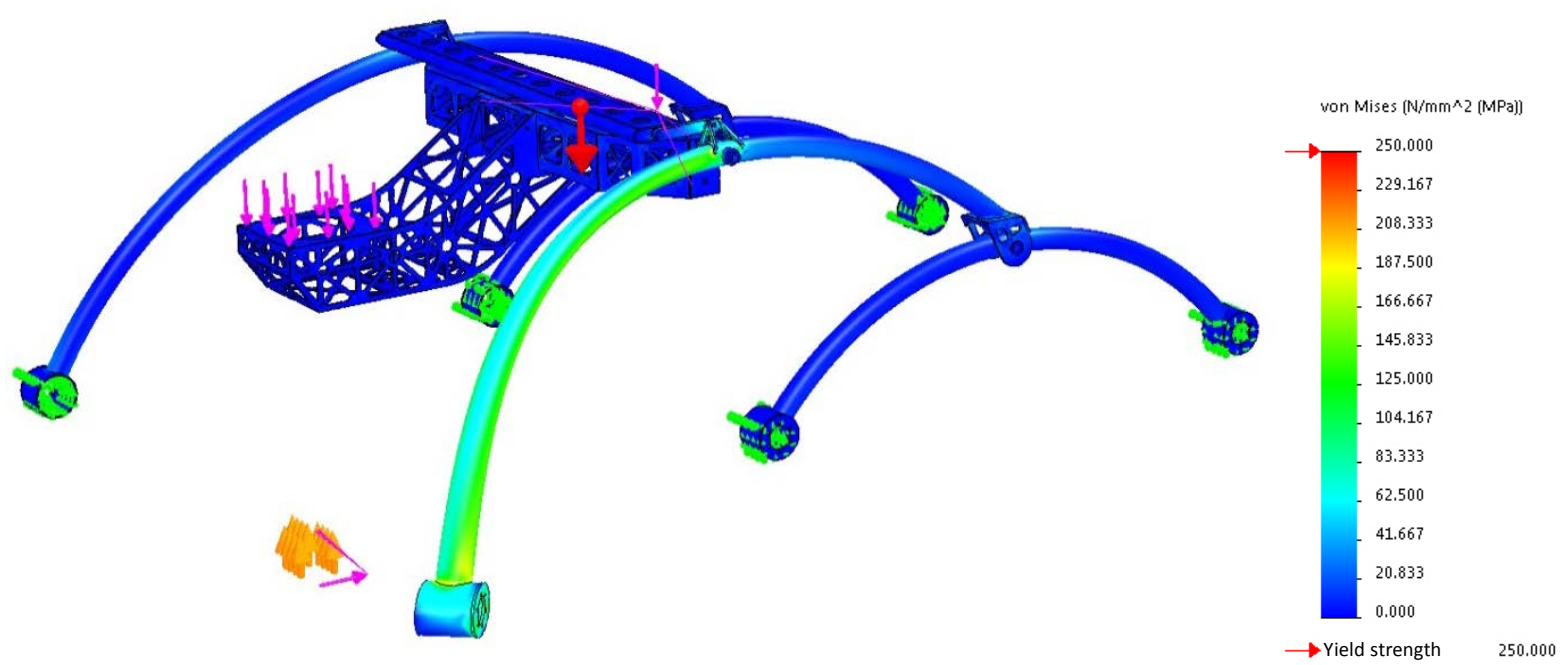

Fig. 6: Second scenario the von Mises stresses

On the basis of the presented results it can be stated that the suspension can collide with obstacles during challenges with no harm to the construction. An increase in speed of the rover will greatly increase stress and finally will lead to the damage of the suspension. During collision the suspension and frame are not the only issues. The separate studies on durability of the 3D printed wheels were also done.

\section{Conclusions}

On the basis of the obtained results it can be stated that the greatest displacements are present in the second scenario, because the force acts on the great distance in relation to the swingarm fixation point. However, it is not dangerous for the construction because the level of stress does not exceed the maximum elastic stress. In the case when the obtained magnitudes of stress and displacements are becoming problematic an increase of the pipe thickness of the swingarm or the change of the shape of the cross-section should be a solution.

After the analysis of all results, the frame and the suspension have been produced. Finally the Modernity II rover has participated in University Rover Challenge 2018 and finished them in the first place among over 90 teams. The project has met all the requirements.

In future the dynamical as well as fatigue studies are planned in order to increase the reliability of the rover.

\section{Acknowledgement}

This work was supported within the BS/PB 1-101/302/17/P.

\section{References}

PCz Rover Team (2019) http://rover.pcz.pl/

Pierzgalski, M., Ptak, P., Cekus, D., and Sokół, K. (2017) Modeling and Stress Analysis of a Manipulator Mounted on a Mars Rover. Procedia Engineering, 177, pp 121-126.

Ptak, P., Pierzgalski, M., Cekus, D., and Sokól, K. (2017) Modeling and Stress Analysis of a Frame with a Suspension of a Mars Rover. Procedia Engineering, 177, pp 175-181.

Solidworks (2016) http://help.solidworks.com/2016/polish/solidworks/sldworks/c_introduction_toplevel_topic.htm University Rover Challenge (2018) http://urc.marssociety.org/home/about-urc/urc2018-scores 